\title{
MANCHESTER
}

1824

†过

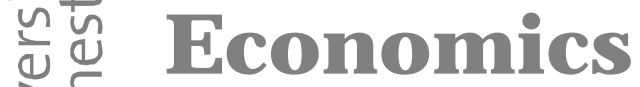

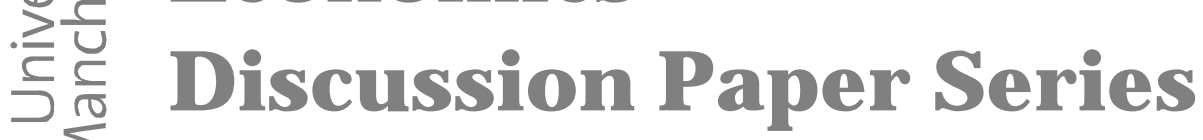

E

\section{WELFARE ECONOMICS OF "FINANCIAL \\ FAIR PLAY” IN A SPORTS LEAGUE WITH BENEFACTOR OWNERS}

\author{
Paul Madden
}

October 2012

Economics

School of Social Sciences

The University of Manchester

Manchester M13 9PL 


\title{
WELFARE ECONOMICS OF "FINANCIAL FAIR PLAY" IN A SPORTS LEAGUE WITH BENEFACTOR OWNERS
}

\author{
Paul Madden
}

\begin{abstract}
$\underline{\text { Abstract }}$ With European soccer leagues in mind, a novel model of club owner objectives nests standard profit (and win) maximization, but adds benefactor behaviour where owners inject personal funds to increase their team's quality. A "generosity" parameter differentiates owners; parameter value zero equates to profit maximizers, with benefactors emerging at sufficiently positive values. The model is used to investigate consequences of UEFA's "Financial Fair Play" regulations (FFP) for the league, aimed to preclude benefactor injections. Assuming (post-Bosman) a relatively large elasticity of talent supply to the league, FFP is a poor regulatory device, creating welfare losses for fans, owners and players.
\end{abstract}

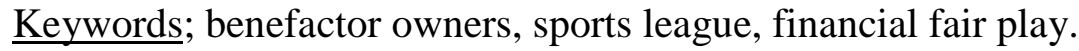

$\underline{\text { JEL classification numbers; }}$ L10, L83

Acknowledgement; I am grateful to Egon Franck for e-mail interchanges that have significantly enhanced my understanding of UEFA's Financial Fair Play regulations. In addition the paper has benefited from comments from audiences at the conferences of the European Association for Research in Industrial Economics (EARIE, Rome 2012) and the European Sports Economics Association (ESEA, London 2012), and EARIE discussant Michael Reksulak. Any remaining misunderstandings, and all views expressed, are solely those of the author.

Author Paul Madden, School of Social Sciences, University of Manchester, Manchester M13 9PL; e-mail, Paul.Madden@manchester.ac.uk 


\section{INTRODUCTION}

Benefactor ownership of a club in a professional sports league (alternatively "sugardaddy ownership" in Lang et al. (2011)) is taken here to mean that the club owners are willing to inject their own funds into the club so as to increase expenditure on playing talent and the resulting team quality. The various national European soccer leagues seem to offer a number of examples, the best-known apparent such cases currently being Roman Abramovich at Chelsea and Sheikh Mansour at Manchester City in the English Premier League (EPL). Such willing (and presumably benefactor utility enhancing) injections of funds have however been seen as the source of problems for the soccer industry. Indeed UEFA has recently drawn up "Financial Fair Play" (FFP) regulations whereby clubs must expend on players no more than their soccer-related revenue, effectively precluding such benefactor fund injections (UEFA (2010a,b)); failure to comply by any club that is successful enough in their own national league to qualify for one of UEFA's European level club competitions will lead to exclusion from that competition. In addition, it has been suggested to the recent UK Parliamentary enquiry into UK soccer governance that FFP might be imposed systematically on all clubs in the EPL, and the issue is still under ongoing discussion in the media and amongst owners ${ }^{1}$.

The paper presents a simplified but quite novel economic model of a sports league which, under laissez-faire, leads to benefactor behaviour by some owners. The model determines endogenously owner injections of funds, team qualities, match ticket prices for fans, and player salaries, plus the utilities accruing to fans, owners and players. The impact on these endogenous variables of the introduction of FFP can then be traced, allowing an evaluation of this regulatory policy. The central finding is clear and decidedly negative for FFP - if the supply of playing talent to the league is sufficiently elastic (as may be most plausible in the post-Bosman European soccer context), imposition of FFP makes all parties (fans, owners and players) worse off, primarily because of the adverse impact it has on all team and league qualities.

The major modelling innovation provided by the paper is its specification of owner objectives, which nests as special cases the objectives of profit maximization and win maximization that have been the focus of most existing literature on sports leagues, and which also brings in the possibility of benefactor behaviour with owners injecting their own funds to increase team quality. Of the benefactor motives suggested by Franck (2010), that assumed here is a pure selfish consumption motive, perhaps analogous to race horse ownership (Franck (2010, p.117)). Just as race horse ownership offers negative financial benefits (Gamrat and Sauer (2000), DeGennaro (2003)), and ownership may be motivated by a consumption benefit (the thrill of the race day experience, the enjoyment of seeing your horse win, particularly in an exciting, high quality champion race...), so too perhaps with ownership of a soccer club. The exact specification ${ }^{2}$ assumes that owner consumption benefits depend on

\footnotetext{
${ }^{1}$ In fact, such an imposition of FFP (with variations) has now been made on all clubs in the English Football League (tiers 2,3 and 4 below the EPL).

2 The specification here is quite different from that of Lang et al. (2011), the only other paper known to the author that addresses benefactor (sugar-daddy) ownership, but without the FFP focus here; we comment further on Lang et al. (2011) in various later remarks.
} 
relative and absolute team qualities (similar to fan utility, as discussed below), but vary across owners via a "generosity" parameter. When this parameter is large benefactor behaviour emerges with positive fund injections. For European soccer, win maximization is the most common club objective assumed in previous literature (see, for instance, Garcia-del-Barrio and Szymanski (2009), Kesenne (2007a,b), Madden (2012), Madden and Robinson (2012)), whereby clubs aim to maximize team quality subject to a zero profit budget constraint, and such behaviour (with zero injections) also appears here at a critical lower value of the generosity parameter. For lower still values of this parameter, owners start to take profits out of the club ("profit takers", with negative injections), reaching standard profit maximizing behaviour when the parameter is zero and the owner gets no consumption benefit from ownership. The paper thus provides a rich and generalised set of leagues characterised by this range of (possibly hybrid) owner behaviour, brought to bear here on the FFP issue, but of potentially much wider application.

Other fundamentals of the model, and the equilibrium concept used, also embody some novel features that are worthy of immediate note. First, in European soccer (particularly since the Bosman ruling) the national leagues have engaged in fierce inter-league competition for playing talent. A number of economic models (e.g. Dietl et al. (2009), Lang et al. (2011), Madden (2012), Madden and Robinson (2012)) have addressed varying aspects of this European context by focusing on a single league, and capturing the fierce talent competition by assuming a perfectly (infinitely) elastic supply of talent to the league at an exogenous wage per unit of talent. Whilst this assumption does capture the fierce talent competition in an extreme way, it does preclude any inflation/deflation of individual player salaries because of the fixed wage per unit of talent. So, whilst our focus is also on a single league in the European spectrum (e.g. the EPL), we generalize the elasticity assumption to allow large but finite elasticity of talent supply, capturing the post-Bosman world in a more realistic way, and bringing player salary changes onto the agenda.

Secondly, as usual, clubs have disjoint sets of fans (their "fanbases") whose utility depends on the relative quality of their team compared to rivals; in addition this utility is also a function of absolute team qualities. The dependence is such that fans would divide a given amount of talent between themselves and rivals in a way that favoured their own team to some extent, but not too much, otherwise games become too onesided - there is some preference for uncertainty of outcome. More importantly the specification assumes that increases in away team quality (ceteris paribus) are a good thing for home fans, to produce the implied and empirically observed positive effect of away team quality on home attendance (Buraimo and Simmons (2008)).

Finally, as usual, clubs are in competition for the supply of talent to the league, and have monopoly power over their fanbase in match ticket sales. However, it is explicitly assumed here that the number of clubs is "large", so that strategic interactions between individual clubs in the talent market can be ignored, and individual clubs cannot influence the wage per unit of talent. Madden (2011) discusses the modelling of sports leagues when numbers are not large in this sense, and game-theoretic equilibrium concepts are needed. Instead we bypass this necessity, justifying perfect competition in the talent market directly by the large numbers. The reason for the large league assumption is simply that it facilitates derivations in the imperfect elastic talent supply case, compared to the game-theoretic alternative. 
Section 2 sets out in detail the fundamentals of the model, as outlined above. Section 3 analyses league equilibrium under laissez-faire, and Section 4 derives the negative consequences of FFP. Section 5 offers further discussion of the model and its results, including the large league (and its equilibrium) concept in Section 5.1, the likely impact of broadcasting income in Section 5.2, some consequences of inelastic talent supply (instead of the assumed high elasticity) in Section 5.3, and some empirical issues arising in Section 5.4. Section 6 concludes.

\section{THE MODELLING FRAMEWORK}

The fundamentals ${ }^{3}$ of the model are: (1) the set of clubs in the league; (2) the supply of talent to the league; (3) the utility functions of fans; (4) the objective functions of club owners. This section describes the assumptions on fundamentals, and derives some of their consequences, before introducing the solution (league equilibrium) concept used, in Section 3 for laissez-faire and in Section 4 for FFP. Madden (2011) argued for a "strategic market game" equilibrium concept if the numbers of clubs is sufficiently small that strategic interactions between individual clubs cannot be ignored, and referred to an alternative "large league" equilibrium concept ${ }^{4}$ for the setting where club numbers are sufficiently large that strategic interactions between individual clubs can be ignored. For tractability reasons this paper takes the large league route, initiated in the next subsection, and discussed further in Section 5.1.

\subsection{Clubs}

The league consists of an exogenously given set of clubs, whose teams play each other over the season with home and away games in stadiums of capacity large enough so as to be never binding on match attendance, and we abstract from stadium costs as is usual in the literature. To capture the large league we follow the standard microeconomics procedure and idealise with the assumption that there is a continuum of clubs of 2 types, with a mass of size 1 of each type $i=1,2$, rather than the common 2 club assumption; type 1 clubs will be "big market clubs", in a sense to be made precise below. Each club has an owner, referred to in the singular, although this is inessential.

\subsection{Talent supply}

On the input side the supply of playing talent to the league, $S(w)$, is constant elastic, with elasticity $\varepsilon \in[0, \infty]$ : that is, $S(w)=w^{\varepsilon}$ if $\varepsilon<\infty$ and $w=1$ if $\varepsilon=\infty$, where $w$ denotes the price of a unit of playing talent, so the talent supply curve is vertical at quantity 1 if $\varepsilon=0$, horizontal at wage 1 if $\varepsilon=\infty$, and upward sloping through the (wage, quantity) points $(0,0)$ and $(1,1)$ otherwise. As remarked in the introduction, we are thinking that $\varepsilon$ will be relatively large for the post-Bosman world, but probably less than the infinity assumed in some earlier literature. $t_{\text {in }} \geq 0, n \in[0,1]$ will denote the allocation of playing talent to type $i(=1,2)$ club $n(\in[0,1])$, also referred to as the

\footnotetext{
${ }^{3}$ Sometimes alternatively referred to as the primitives, characteristics or data of the model.

${ }^{4}$ The idea first appears in Madden (2010).
} 
quality of team in, and is a choice variable for club in; $w t_{i n}$ is then the club's expenditure on playing talent, which is the only club cost.

\subsection{Fan utility}

On the output side the owners of club in also make decisions on its price $\left(p_{\text {in }}\right)$ for season tickets that allow entry to all subsequent home games over the season; in the terminology introduced by Fort and Quirk (2011), the model is that of a "season ticket league". There are disjoint sets of fans of each club in who feel an (exogenously given) affinity to the club and are assumed to be the only potential buyers of its season tickets. Fans of in are heterogeneous in their willingness to pay for tickets, denoted $v\left(t_{i n}, \bar{t}\right)-x$, where the heterogeneity parameter is $x \geq 0$, and where $v\left(t_{i n}, \bar{t}\right)$ is the maximum valuation, assumed to depend on the fan's own team's quality $\left(t_{i n}\right)$ and the average quality of other teams $(\bar{t})$; implicitly we are assuming that the full fan utility function is quasi-linear, defined over a numeraire (endowment $y$ and large) and the match ticket. Full utility is then $y$ without the ticket and $y-p_{i}+v\left(t_{i n}, \bar{t}\right)-x$ with the ticket, so that a fan will demand a ticket if $x \leq v\left(t_{i n}, \bar{t}\right)-p_{i n}$. A Cobb-Douglas specification is assumed for tractability, $v\left(t_{i n}, \bar{t}\right)=t_{i n}^{\alpha} \bar{t}^{\beta}$, where $\alpha>\beta>0$ and $\alpha+\beta<1 / 2$. A number of features of this specification are worthy of comment. First, we may rewrite $v\left(t_{i n}, \bar{t}\right)=\left(t_{i n} / \bar{t}\right)^{\alpha} \bar{t}^{\alpha+\beta}$, showing how fan utility depends not only on the relative quality of a fan's team but also on the absolute quality level in the league. Here $t_{i n} / \bar{t}$ is the analogue for the large league setting of the Tullock contest success function, commonly assumed to be the only determinant of fan utility, but supplemented here by dependence on absolute team qualities (via $\bar{t}^{\alpha+\beta}$ ); remark 1 below elaborates on this point. Secondly, it is important that fan utility depends positively not only on home team quality but also on away team qualities so that $\alpha, \beta>0$; Remark 1 below will point to empirical evidence in support. Thirdly, $\alpha(\beta)$ measures the elasticity of fan utility (and hence, below, that of ticket demand and gate revenue) with respect to increases in home (away) team quality, and we assume also that $\alpha>\beta$, to reflect the previous affinity of fans to their team. ${ }^{5}$. Finally $\alpha+\beta<1 / 2$ ensures concavity of various objective functions in maximization problems that follow.

The total number of fans of a club of type $i$, its "fanbase", is $\mu_{i}$ where, without loss of generality, type 1 clubs are the "big market clubs" in that $\mu_{1} \geq \mu_{2}$. It is also assumed that the number of fans exceeds stadium capacity ${ }^{6}$, which in turn is never a binding constraint on attendance. For each type of club it is assumed that $x$ is uniformly distributed over $[0,1]$.

The consequences of the above specification of fan utility for season ticket demand and gate revenues are easily seen. The fraction of fans of club in demanding a ticket

\footnotetext{
${ }^{5}$ Complete fan preference for uncertainty of outcome would imply $\alpha=\beta$; Buraimo and Simmons (2008) find preference for uncertainty of outcome to be weak $-\alpha>\beta$ certainly.

${ }^{6} c$ could depend on club type, but this adds nothing of value, given the stadium capacity assumptions.
} 
will be $v\left(t_{i n}, \bar{t}\right)-p_{\text {in }}$ and total demand is $D_{\text {in }}\left(t_{i n}, \bar{t}, p_{\text {in }}\right)=\mu_{i}\left[v\left(t_{i n}, \bar{t}\right)-p_{\text {in }}\right]$. If prices are chosen to maximize revenues (monopoly pricing) then $p_{i n}=\frac{1}{2} v\left(t_{i n}, \bar{t}\right)$, producing demand of $\frac{1}{2} \mu_{i} v\left(t_{i n}, \bar{t}\right)$ and gate revenues ${ }^{7}$ of $R_{i n}\left(t_{i n}, \bar{t}\right)=\frac{1}{4} \mu_{i} v\left(t_{i n}, \bar{t}\right)^{2}$. Gate revenues are the only soccer-related club revenues. Notice that under our large stadium capacity and season ticket assumptions, the resulting demand can also be taken to be the attendance at each of the home games of club in.

$\underline{\text { Remark } 1}$ The specification implies that fan utilities, ticket demands, gate revenues and attendances will all be increasing in both home and away team qualities, stemming from the assumption that $v\left(t_{i n}, \bar{t}\right)$ is increasing in both its arguments. There is a significant empirical literature on the determinants of soccer attendances - see, for instance, Buraimo and Simmons (2008, 2009), Buraimo et al. (2009), Forrest and Simmons (2002), Forrest et al. (2005). In particular, Buraimo and Simmons (2008, p.151-152) find uniformly positive effects of both home and away team quality on attendance for the EPL, providing empirical support for the assumption that $v\left(t_{\text {in }}, \bar{t}\right)$ is increasing in both its arguments.

It needs to be stressed again that this feature of the model is important, and at variance with many models in the existing literature, which assume that gate revenues (or the more fundamental ticket demand functions or fan utility) depend only on the relative quality of the home team. Madden (2011) provides an extended critique of existing literature in this aspect. In a nutshell it seems completely implausible to assume as a fundamental that gate revenues (or ticket demand or fan utility) are unchanged if all team qualities increase by positive amounts in a way that keeps constant relative team qualities (and hence win percentages and competitive balance). Yet such an assumption is very prevalent in the literature, including Lang et al. (2011) who also address benefactor (sugar-daddy) ownership, with a focus on competitive balance and welfare (as we have here also), and revenue sharing (rather than our FFP). Fan utility (and also owner utility which is a linear combination of profit and win percentage) is homogeneous of degree zero in team qualities, implying (implausibly in this author's view) that uniform expansion of all team qualities (leaving win percentages and competitive balance unchanged) would produce no change in fan (or owner) utility, ticket demand or gate revenue. Later remarks discuss further Lang et al. (2011).

\subsection{Owners}

Owners of clubs of type $i(=1,2)$ are assumed to have quasi-linear utility functions of the form, for $n \in[0,1]$ and with $v\left(t_{i n}, \bar{t}\right)=t_{i n}^{\alpha} \bar{t}^{\beta}$;

$$
U_{\text {in }}=\lambda_{i} u\left[v\left(t_{\text {in }}, \bar{t}\right)\right]-I_{\text {in }}+m_{\text {in }}
$$

Here $m_{i n}$ is the owner's wealth and $I_{i n}$ denotes funds injected by the owner; $I_{\text {in }}$ could be negative, indicating the owner is taking money out of the club, rather than providing funds. We assume throughout that $m_{i n}-I_{i n}>0-$ owners are sufficiently

\footnotetext{
${ }^{7}$ In the Cobb-Douglas case $R_{i n}\left(t_{i n}, \bar{t}\right)=\frac{1}{4} \mu_{i} t_{i n}^{2 \alpha} \bar{t}^{2 \beta}$ the derivative with respect to $t_{\text {in }}$ (marginal revenue) goes to infinity as $t_{\text {in }} \rightarrow 0$, a feature that stems from the Inada conditions satisfied by the Cobb-Douglas. In Madden (2010) it is shown how marginal revenue typically goes to zero as $t_{\text {in }} \rightarrow 0$ without such Inada conditions, and equilibrium existence problems follow which are absent here.
} 
wealthy to provide any fund injection that is optimal for them. In the first term on the right, $u$ is some increasing function of $v\left(t_{i n}, \bar{t}\right)$, reflecting the discussion in the introduction of benefactor motivation here - it is a pure, selfish consumption motive that drives any fund injections, its value to the owner dependent on the resulting team qualities in a similar way to that of fan utility. $\lambda_{i} \geq 0,1=1,2$ are parameters that allow some heterogeneity between the consumption benefits accruing to the 2 owner types, and are referred to as the owner "generosity" parameters - higher values of $\lambda_{i}$ indicate greater consumption benefits from ownership which lead (as will be seen) to larger injections.

Given that our motive for fund injection does not entail any explicit need or desire to curry favour with fans, any owner would price tickets at the revenue maximizing (monopoly) level ${ }^{8}$, leading to gate revenue $R_{i}\left(t_{i n}, \bar{t}\right)$, as described at the end of the last sub-section. It follows that it would require an injection of $I_{i n}=w t_{i n}-\frac{1}{4} \mu_{i} t_{i n}^{2 \alpha} \bar{t}^{2 \beta}$ (the negative of profits) to produce a team of quality $t_{i n}$. Because of the large number of clubs in the league, each individual club has no influence over the wage per unit of talent $(w)$ and the average quality of teams $(\bar{t})$. Under laissez-faire where there are no FFP restrictions on owner injections, the utility maximization problem faced by the owner of club in is;

$$
\max _{t_{i n}} U_{i n}=\lambda_{i} u\left[v\left(t_{i n}, \bar{t}\right)\right]+\frac{1}{4} \mu_{i} t_{i n}^{2 \alpha} \bar{t}^{2 \beta}-w t_{i n}+m_{i n}
$$

Because the Cobb-Douglas function satisfies the Inada conditions, any solution to (2.2) when $\bar{t}>0$ has $t_{\text {in }}>0$ also; attention is restricted to $\bar{t}, t_{i n}>0$ therefore. It is clear that the specification nests the textbook profit maximization objective in the special case where $\lambda_{i}=0$. It is useful for the model to nest also the other classic textbook objective of win maximization - we can then claim to be generalising beyond the 2 most prevalent club objectives found in previous literature. This requires that the solution to (2.2) always leads to zero profits - the owner will then choose the largest value of $t_{i n}$ subject to the budget balance of zero profit, exactly the same as the textbook win-maximizer. The requirement is satisfied only in a special case of (2.2):

Lemma 1 The solution to (2.2) implies always (i.e. for all $\bar{t}$ ) zero profits, and thus is equivalent to win maximization, if and only if $\lambda_{i} u\left[v\left(t_{i n}, \bar{t}\right)\right]=\frac{1-2 \alpha}{8 \alpha} \mu_{i} t_{i n}^{2 \alpha} \bar{t}^{2 \beta}+A$, for some arbitrary constant $A$.

Proof See appendix.

There is no loss of generality in putting $A=0$; it can be subsumed into the constant $m_{\text {in }}$ term. It also follows from Lemma 1 that $\lambda_{i}=\frac{1-2 \alpha}{8 \alpha} \mu_{i} / B$ and ${ }^{9}$ $u\left[v\left(t_{i n}, \bar{t}\right)\right]=B t_{i n}^{2 \alpha} \bar{t}^{2 \beta}$, for some $B>0$, and, again without loss of generality, we can

\footnotetext{
${ }^{8}$ Different ticket pricing policies would emerge if the owner objective included, for some reason, a desire to please fans; Madden (2012), Madden and Robinson (2012) address ticket pricing when such fan welfare considerations enter club objectives.

${ }^{9}$ The fact that $u\left[v\left(t_{i n}, \bar{t}\right)\right]$ is quadratic in $v\left(t_{i n}, \bar{t}\right)$ is consistent with the increasing returns nature of the specification suggested in Franck (2010, p.117), following the argument of Rosen (1981).
} 
put $B=1$. Thus (2.2) now becomes the following final specification of the owner utility maximization problem (where the constant $m_{\text {in }}$ has been omitted);

$$
\max _{t_{i n}} U_{i n}=\left(\frac{1}{4} \mu_{i}+\lambda_{i}\right) t_{i n}^{2 \alpha} \bar{t}^{2 \beta}-w t_{i n}
$$

Some first consequences of the specification are as follows. The objective function in (2.3) is strictly concave in $t_{i n}$, so the solution (which defines the club's talent demand function, and will be strictly positive for all $\bar{t}>0$ ) is given by the first-order condition;

$$
2 \alpha\left(\frac{1}{4} \mu_{i}+\lambda_{i}\right) t_{i n}^{2 \alpha-1} \bar{t}^{2 \beta}=w
$$

Notice that talent demand will be a decreasing function of $w$ and an increasing function of $\bar{t}$. The latter indicates an aggregate strategic complementarity - it is optimal for any owner to increase player expenditure and team quality if other owners do so.

Recalling that $I_{\text {in }}=w t_{\text {in }}-\frac{1}{4} \mu_{i} t_{\text {in }}^{2 \alpha} \bar{t}^{2 \beta},(2.4)$ implies that desired injections are;

$$
I_{\text {in }}=\left[2 \alpha \lambda_{i}-\frac{1}{4} \mu_{i}(1-2 \alpha)\right] t_{i n}^{2 \alpha} \bar{t}^{2 \beta}
$$

As indicated earlier, larger values of $\lambda_{i}$ lead to larger injections. The critical value of $\lambda_{i}$ is $\hat{\lambda}_{i} \equiv \mu_{i} \frac{1-2 \alpha}{8 \alpha}$, since $I_{\text {in }}$ always has the sign of $\lambda_{i}-\hat{\lambda}_{i}$, which leads to the following extended terminology; owner $i$ is a benefactor if $\lambda_{i}>\hat{\lambda}_{i}$, a win-maximizer if $\lambda_{i}=\hat{\lambda}_{i}$ (as we knew from Lemma 1), a profit-taker if $0<\lambda_{i}<\hat{\lambda}_{i}$, and a profitmaximizer if $\lambda_{i}=0$ (as we already also knew). Thus benefactors choose to inject positive funds into the club, whilst profit-takers do the opposite. At the border between these two owner types, the win maximizer makes zero profit, and chooses to behave like the zero-profit constrained win-maximizer studied in existing models. Finally the profit-maximizer takes out of the club maximum profits. (2.4) reports the usual equation of marginal revenue to the wage in the profit-maximizing case of $\lambda_{i}=0$ where owners derive no consumption benefit from ownership. As $\lambda_{i}$ increases marginal revenue is augmented by the positive marginal consumption utility the owner now gets from injecting funds (the funds will still be negative for small $\lambda_{i}$, becoming positive when $\lambda_{i}>\hat{\lambda}_{i}$ ). In general, (2.4) says that the total marginal benefit, namely the sum of marginal revenue and owner marginal consumption utility, equals the wage.

An interesting feature of the owner utility specification is that it nests the standard objective of win maximization subject to zero profits, and that of profit maximization. Thus the ownership structure of the leagues to be studied in what follows includes a league where both types of club are profit maximizers $\left(\lambda_{1}=\lambda_{2}=0\right)$, a league where both are win maximizers ( $\lambda_{1}$ and $\lambda_{2}$ at the required critical value), a league where both are benefactors who inject positive funds ( $\lambda_{1}$ and $\lambda_{2}$ sufficiently large), plus all hybrid leagues with mixtures of (and intermediates between) these owner types. 


\section{LAISSEZ-FAIRE}

This section describes league equilibrium under laissez-faire, and shows how it changes as the benefactor generosity parameters $\lambda_{1}$ and $\lambda_{2}$ vary. The latter comparative statics exercise will facilitate the later analysis of the impact of FFP, which will be seen to be equivalent to certain reductions in $\lambda_{1}$ and $\lambda_{2}$.

Equilibrium under laissez-faire is a set of (strictly positive) values for the talent allocations to clubs (and so the average league talent level), the wage per unit of talent and season ticket prices such that the talent market clears, all season ticket markets clear and fans and owners are making utility maximizing decisions (about, respectively, ticket demand and talent demand/ticket prices). In equilibrium, all clubs of the same type will make the same decisions, so $t_{i n}=t_{i}, p_{i n}=p_{i}$ say, $i=1,2, n \in[0,1]$. Thus equilibrium under laissez-faire is defined by $t_{1}, t_{2}, \bar{t}, w$ and $p_{1}, p_{2}$ (all strictly positive) such that;

$$
\begin{aligned}
& 2 \alpha a_{i} t_{i}^{2 \alpha-1} \bar{t}^{2 \beta}=w, i=1,2 \text { where } a_{i} \equiv \frac{1}{4} \mu_{i}+\lambda_{i} \\
& \bar{t}=\frac{1}{2}\left(t_{1}+t_{2}\right)=\frac{1}{2} w^{\varepsilon} \text { if } \varepsilon \in[0, \infty) \text { and } w=1 \text { if } \varepsilon=\infty \\
& p_{i}=\frac{1}{2} t_{i}^{\alpha} \bar{t}^{\beta}, i=1,2
\end{aligned}
$$

(3.1) ensures utility maximizing owner talent demand (from (2.4)), (3.2) is the talent market clearing condition, and, given utility maximizing ticket demand from fans, (3.3) ensures that owners supply the demand at (owner) utility maximizing prices. It is easy (if cumbersome) to find explicit solutions for unique equilibrium values of all variables. Some are found in the appendix, but for the text we report merely:

Lemma 2 There exists a unique equilibrium under laissez-faire.

Proof See appendix.

Turning to comparative statics, consider first equilibrium competitive balance. An indicator of competitive balance is the ratio of team qualities $t_{1} / t_{2}$, which is, using (3.1);

$$
\frac{t_{1}}{t_{2}}=\left(\frac{\lambda_{1}+\frac{1}{4} \mu_{1}}{\lambda_{2}+\frac{1}{4} \mu_{2}}\right)^{\frac{1}{1-2 \alpha}}
$$

The league is perfectly balanced $\left(t_{1} / t_{2}=1\right)$, if $\frac{1}{4} \mu_{1}+\lambda_{1}=\frac{1}{4} \mu_{2}+\lambda_{2}$; otherwise the club type with the highest value of $\frac{1}{4} \mu_{i}+\lambda_{i}$ will have the best quality teams and there will be some competitive imbalance. Thus the bigger fanbase clubs (type 1) may not have the better teams (i.e. $t_{1}$ may be lower than $t_{2}$, as found also in Lang et al. (2010)), if the owners of clubs with the smaller fanbase derive sufficiently large consumption benefits ( $\lambda_{2}$ large enough). Generally, $t_{1} / t_{2}$ is increasing in $\lambda_{1}$ and decreasing in $\lambda_{2}$, also seen in the contour map for $t_{1} / t_{2}$ in Figure 1, which allows one to read off the consequences for competitive balance of changes in owner objectives.

Remark 2 For instance, and replicating the comparison of Lang et al. (2010), compare the competitive balance of a league with 2 profit-maximizers 
$\left(\lambda_{1}=\lambda_{2}=0\right)$ first with a league where the big club (1) now has an owner with a larger $\lambda_{1}(>0)$. Initially the contours show $t_{1} / t_{2}>1$, and there is some competitive imbalance with the big club having the better team; as $\lambda_{1}$ increase $t_{1} / t_{2}$ increases, and competitive balance deteriorates, the big club team getting even better relatively. Now suppose instead that it is the smaller club that undergoes the increase in owner generosity to some $\lambda_{2}(>0)$. The contours reveal that initially, for $\lambda_{2}<b$, competitive balance is better than in the profit-maximizing league, perfect balance being attained when $\lambda_{2}=b$; thereafter the increasing generosity of the small club owners means that they now have the better team, competitive balance starts to deteriorate and eventually will become worse than when both clubs were profitmaximizers. The result in Proposition 1 of Lang et al. (2010) is qualitatively the same. Figure 1 shows how comparisons can be made here for pairs of leagues with arbitrary generosity parameters, not just where at least 1 type of club is a profit-maximizer ${ }^{10}$.

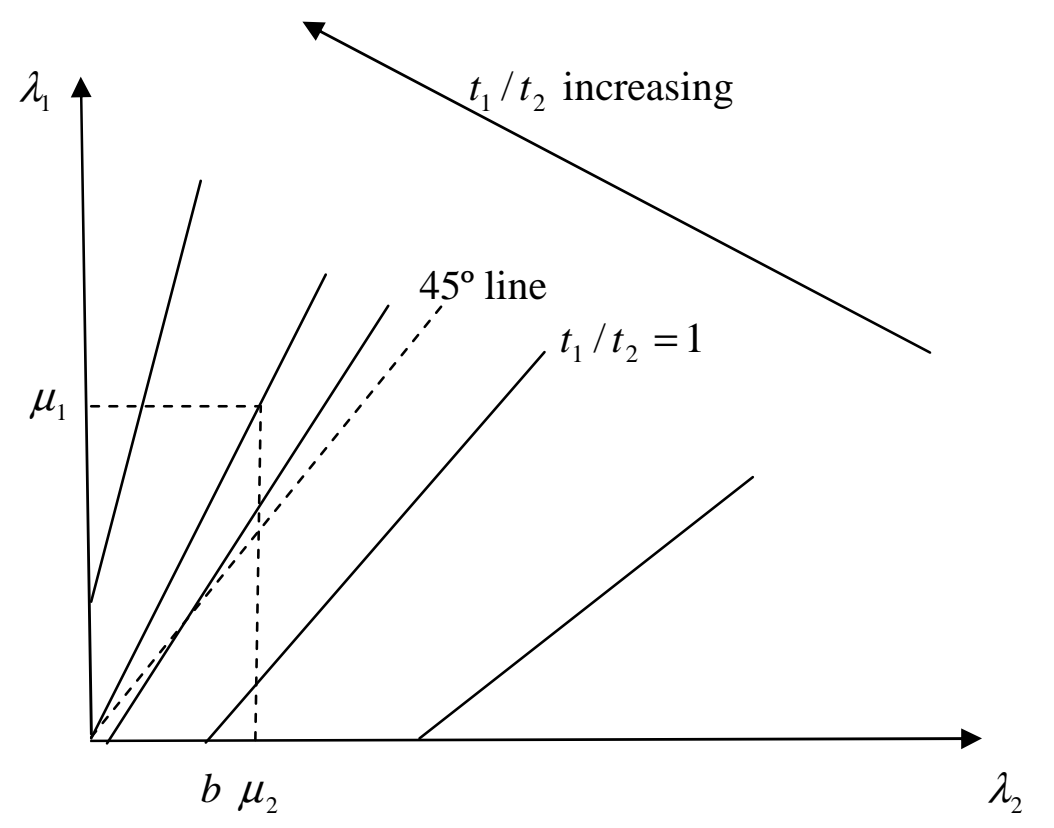

Figure 1; Equilibrium relative team quality contours $\left(t_{1} / t_{2}\right)$

Next is the effect of changes in $\lambda_{i}$ on absolute, as opposed to relative, equilibrium team qualities. To analyse this issue, it is helpful to start with the extreme elasticity special cases, $\varepsilon=0$ and $\varepsilon=\infty$.

When $\varepsilon=0$ an increase in $\lambda_{i}$ increases $t_{i} / t_{j}$ (as noted generally and in Figure 1), but because talent supply is fixed, $t_{i}$ goes up and $t_{j}$ goes down. From (3.1) with $i=j, w$ must go up, as $\bar{t}$ is unchanged. Thus an increase in $\lambda_{i}$ produces an increase in $t_{i}$, a reduction in $t_{j}$, and an increase in $w$, with no change in $\bar{t}$. The same will happen if $\varepsilon$ is positive but small, except that the small change in the slope of the talent supply curve will now lead to a small increase in $\bar{t}$.

\footnotetext{
${ }^{10}$ In a footnote Lang et al.(2010) also compare the league of 2 profit-maximizers with their analogue of leagues along the $45^{\circ}$ line in Figure 1. Figure 1 shows that competitive balance increases continuously as $\lambda\left(=\lambda_{1}=\lambda_{2}\right)$ increases, again qualitatively the same as in Lang et al. (2010).
} 
When $\varepsilon=\infty$ and $w=1$, an increase in $\lambda_{i}$ will produce an increase in demand for talent from type $i$ clubs, from (3.1), assuming first that $\bar{t}$ remains at its equilibrium value. But this increase would lead to an increase in $\bar{t}$, with $t_{j}$ at its original equilibrium value, and, because of the strategic complementarity, this now leads to an increase in talent demand from type $j$ clubs too. This further increases $\bar{t}$, further increasing $t_{i}$, and this "tatonnement" finishes at a new equilibrium where both $t_{i}$ and $t_{j}$ are increased. The reason why $\lambda_{i}$ increases lead to increases in $t_{j}$ is important - as $\lambda_{i}$ increases, type $i$ clubs increase their own team quality, but this leads to an increase in average league quality $\bar{t}$ (with no change in $w$ ), extra gate revenue for type $j$ clubs from their home games (as their opponent quality has increased on average), and this leads to the increase in quality of type $j$ clubs too. Similar outcomes prevail if $\varepsilon$ is finite but large, except that the small upward slope of the talent supply curve will now lead to a small increase in $w$, accompanying the increases in $t_{i}, t_{j}$ and $\bar{t}$.

The above informal arguments indicate that increases in $\lambda_{i}$ will lead to increases in $w$, $t_{i}$ and $\bar{t}$, if $\varepsilon$ is large enough or small enough, with $t_{j}$ increasing at large $\varepsilon$ and decreasing for small $\varepsilon$. The precise statement next shows that the increases in $w, t_{i}$ and $\bar{t}$ always occur, and that there is a critical (positive, finite) value for elasticity where the effect on $t_{j}$ switches:

Proposition 1 If the generosity of type $i$ club owners $\left(\lambda_{i}\right)$ increases then:

(i) the quality of type $i$ clubs $\left(t_{i}\right)$ increases;

(ii) the average quality of all clubs in the league $(\bar{t})$ increases if $\varepsilon>0$ and is unchanged if $\varepsilon=0$;

(iii) the players' wage per unit of talent (w) increases if $\varepsilon<\infty$ and is unchanged if $\varepsilon=\infty$;

(iv) the quality of type $j$ clubs $\left(t_{j}\right)$ also increases if $\varepsilon>1 /(2 \beta)$, but decreases if $\varepsilon<1 /(2 \beta)$.

Proof See appendix.

The reason for the dependence of the switch value of $\varepsilon$ on $\beta$ is as follows. As $\lambda_{i}$ increases and $\bar{t}$ increases, the wage increases by an amount which increases (from 0 when $\varepsilon=\infty$ ) as $\varepsilon$ declines. The increase in $\bar{t}$ will increase the marginal benefit (revenue plus consumption, in (2.4)) accruing to type $j$ club owners by amounts which increase with $\beta$. For type $j$ owners to increase their talent demand also therefore requires that $\beta$ is sufficiently large, or, as in (iv), that $1 /(2 \beta)$ is sufficiently small.

Consider next the effect on utilities of fans of a type $j$ club that an increase in $\lambda_{i}$ would create if talent supply is relatively elastic $(\varepsilon>1 /(2 \beta))$. From Proposition $1, \bar{t}$ and $t_{j}$ increase. Hence $v\left(t_{j}, \bar{t}\right)$ increases, and so do type $j$ ticket prices, but only to $v\left(t_{j}, \bar{t}\right) / 2$. So for a fan with heterogeneity parameter $x, v\left(t_{j}, \bar{t}\right)-p_{j}-x$ increases, and this creates a Pareto improvement for all fans of any type $j$ club. To be more exact those fans who bought a type $j$ club's season ticket before the change continue to do 
so after, and are strictly better off because of the increased team qualities on view that are less than offset by higher ticket prices; the change will increase demand for season tickets, and new spectators are also strictly better off; fans who attend neither before or after have unchanged utility. But the parallel arguments apply exactly for fans of a type $i$ club (in fact now for any value of $\varepsilon$ ), who also enjoy a Pareto improvement. Thus, increases in $\lambda_{i}$ or $\lambda_{j}$ or both lead to Pareto improvement for all fans, if $\varepsilon>1 /(2 \beta)$.

When supply is not relatively elastic $(\varepsilon<1 /(2 \beta))$, an increase in $\lambda_{i}$ continues to create a Pareto improvement for all fans of type $i$ clubs, since $\bar{t}$ and $t_{i}$ increase. But now $t_{j}$ falls. For $\varepsilon$ below but near $1 /(2 \beta)$, the small fall in $t_{j}$ is more than compensated by the rise in $t_{i}$, and type $j$ club fans continue to enjoy a Pareto improvement. Larger falls in $\varepsilon$ and hence $t_{j}$ will still leave fans of type $j$ clubs better off if $\alpha / \beta$ is relatively small and fans have a relatively low preference for home team quality compared to away team. A new lower critical value of $\varepsilon=\alpha / \beta$ emerges - below this type $j$ are made worse off by the increase in $\lambda_{i}$ :

Proposition 2 If the generosity of type $i$ club owners $\left(\lambda_{i}\right)$ increases then there is a Pareto improvement for all fans of type $i$ clubs; there is also a Pareto improvement for all fans of type $j$ clubs if $\varepsilon>\alpha / \beta$, but type $j$ club fans are worse off if $\varepsilon<\alpha / \beta$.

Proof See appendix.

Since equilibrium ticket prices are $p_{i}=v\left(t_{i}, \bar{t}\right) / 2$, they move monotonically with fan utility. An immediate consequence of Proposition 2 is therefore:

Corollary to Proposition 2 If the generosity of type $i$ club owners $\left(\lambda_{i}\right)$ increases then their season ticket price $\left(p_{i}\right)$ increases; the season ticket price for type $j$ clubs $\left(p_{j}\right)$ also increases if $\varepsilon>\alpha / \beta$, but decreases if $\varepsilon<\alpha / \beta$.

The salary of a player in the league will be [the player's individual talent level] $\times w$, and, from (iii), this will increase as $\lambda_{i}$ increases (if $\varepsilon<\infty$ ), which on any plausible player utility representation will increase the player's utility also.

Consider next the utility of owners. From (2.2) and (3.4)/(3.5), equilibrium owner utility is, for $i=1,2$;

$$
U_{i}=\frac{1-2 \alpha}{2 \alpha} w t_{i}
$$

Since an increase in $\lambda_{i}$ increases both $w$ (at least weakly) and $t_{i}, U_{i}$ also increases. The effect on $U_{j}$ depends on the elasticity:

Proposition 3 If the generosity of type $i$ club owners $\left(\lambda_{i}\right)$ increases then the utility level of owners of type $i$ clubs $\left(U_{i}\right)$ increases; the utility level of owners of type $j$ clubs $\left(U_{j}\right)$ also increases if $\varepsilon>\alpha / \beta$, but decreases if $\varepsilon<\alpha / \beta$.

Proof See appendix. 
Now suppose that both $\lambda_{i}$ and $\lambda_{j}$ increase. In general the detailed implications will depend on how quickly the 2 generosity parameters change. However the following statements are immediate from Propositions 1-3, and are independent of the relative speed of change:

Proposition 4 If the generosity of both types of club owners $\left(\lambda_{i}\right.$ and $\left.\lambda_{j}\right)$ increases then:

(i) the average quality of all clubs in the league $(\bar{t})$ increases (if $\varepsilon>0$ ), and the players' wage per unit of talent $(w)$ also increases (if $\varepsilon<\infty$ );

(ii) the quality of all teams in the league $\left(t_{i}\right.$ and $\left.t_{j}\right)$ increases if $\varepsilon>1 /(2 \beta)$;

(iii) all season ticket prices ( $p_{i}$ and $p_{j}$ ) increase if $\varepsilon>\alpha / \beta$;

(iv) there is a Pareto improvement for all fans if $\varepsilon>\alpha / \beta$;

(v) the utility levels of both owner types $\left(U_{i}\right.$ and $U_{j}$ ) increases if $\varepsilon>\alpha / \beta$.

Recalling that $\varepsilon>1 /(2 \beta)$ implies that $\varepsilon>\alpha / \beta$ (since $1 /(2 \beta)>\alpha / \beta$ as $1 / 2>\alpha$ ), a simple summary statement that now follows is:

Summary statement If talent supply is relatively elastic $(\varepsilon>1 /(2 \beta))$, then an increase in the generosity of at least one owner type leads to increases in all fan and owner utility levels, all season ticket prices and (if $\varepsilon<\infty$ ) in player salaries.

It was seen earlier that increases in the generosity of owners could lead to increases or decreases in competitive balance. It should be stressed that the direction of this change in competitive balance is completely irrelevant for the conclusions of the summary statement and the previous Propositions. For instance, suppose that $i=1$ (so that clubs of type $i$ are the big market clubs), and suppose that they also have the more generous owners $\left(\lambda_{1}>\lambda_{2}\right)$. Then the big market clubs will certainly have the relatively better teams in the laissez-faire equilibrium $\left(t_{1} / t_{2}>1\right.$ from (3.4)). A further increase now in $\lambda_{1}$ will generate (assuming $\varepsilon>1 /(2 \beta)$ ) the positive effects on team qualities, salaries and utilities noted above, whilst producing (see Figure 1) a further increase in $t_{1} / t_{2}$ and a worsening in competitive balance.

Remark 3 The positive welfare impact of increases in owner generosity on fans, owners and players means that just about any plausible concept of aggregate surplus will increase also - any adverse changes to competitive balance are irrelevant, as noted above. In contrast the welfare conclusions of Lang et al. (2011) are naturally quite different. The absence of any effect of absolute quality on fan or owner utility means that the only thing that matters is competitive balance, and the impact on their aggregate surplus concept of introducing sugar daddies into the profit-maximizing league (as discussed in Remark 2 earlier) is more nuanced - certainly it may be negative (see Proposition 2 of Lang et al. (2011)). 


\section{FINANCIAL FAIR PLAY}

We take FFP to bring into the laissez-faire world the regulation that fund injections cannot be positive. The previous club decision problem (2.3) becomes;

$$
\max _{t_{i j}}\left(\frac{1}{4} \mu_{i}+\lambda_{i}\right) t_{i n}^{2 \alpha} \bar{t}^{2 \beta}-w t_{\text {in }} \text { subject to } I_{\text {in }}=w t_{i n}-\frac{1}{4} \mu_{i} t_{i n}^{2 \alpha} \bar{t}^{2 \beta} \leq 0
$$

Equilibrium under FFP is the same as under laissez-faire, except that the owners' utility maximizing talent demands are from (4.1) rather than (2.3). Analysis of (4.1) produces the following relation between FFP equilibria and laissez-faire equilibria:

Lemma 3 When owner generosity parameters are $\left(\lambda_{1}, \lambda_{2}\right)$, there exists a unique equilibrium under FFP in which the equilibrium values of talent allocations, wage per unit of talent and season ticket prices are the same as in the equilibrium under laissezfaire when the owner generosity parameters are $\left(\bar{\lambda}_{1}, \bar{\lambda}_{2}\right)=\left(\min \left[\lambda_{1}, \hat{\lambda}_{1}\right], \min \left[\lambda_{2}, \hat{\lambda}_{2}\right]\right)$. Proof See appendix.

Figure 2 illustrates the content. If $\lambda_{1} \leq \hat{\lambda}_{1}$ and $\lambda_{2} \leq \hat{\lambda}_{2}$, so neither type of owner is a benefactor and injections are already negative under laissez-faire, then, naturally, the FFP demand that injections are negative has no effect at all, as labelled in Figure 2. If $\lambda_{1} \leq \hat{\lambda}_{1}$ but $\lambda_{2}>\hat{\lambda}_{2}$, type 2 owners are now (the only) benefactors, and would be making positive injections under laissez-faire. The effect of FFP is as if the type 2 owners were turned into win maximizers, namely the FFP equilibrium is the laissezfaire equilibrium with owner generosity parameters $\left(\bar{\lambda}_{1}, \bar{\lambda}_{2}\right)$ where $\bar{\lambda}_{1}=\lambda_{1}$ but $\bar{\lambda}_{2}=\hat{\lambda}_{2}$; the horizontal arrows in Figure 2 illustrate such a mapping from $\left(\lambda_{1}, \lambda_{2}\right)$ to $\left(\bar{\lambda}_{1}, \bar{\lambda}_{2}\right)$. The vertical arrows are for the case where only type 1 owners are benefactors, and the positive slope arrows are where all owners are benefactors, in which case the effect of FFP is as if all owners became win maximizers.

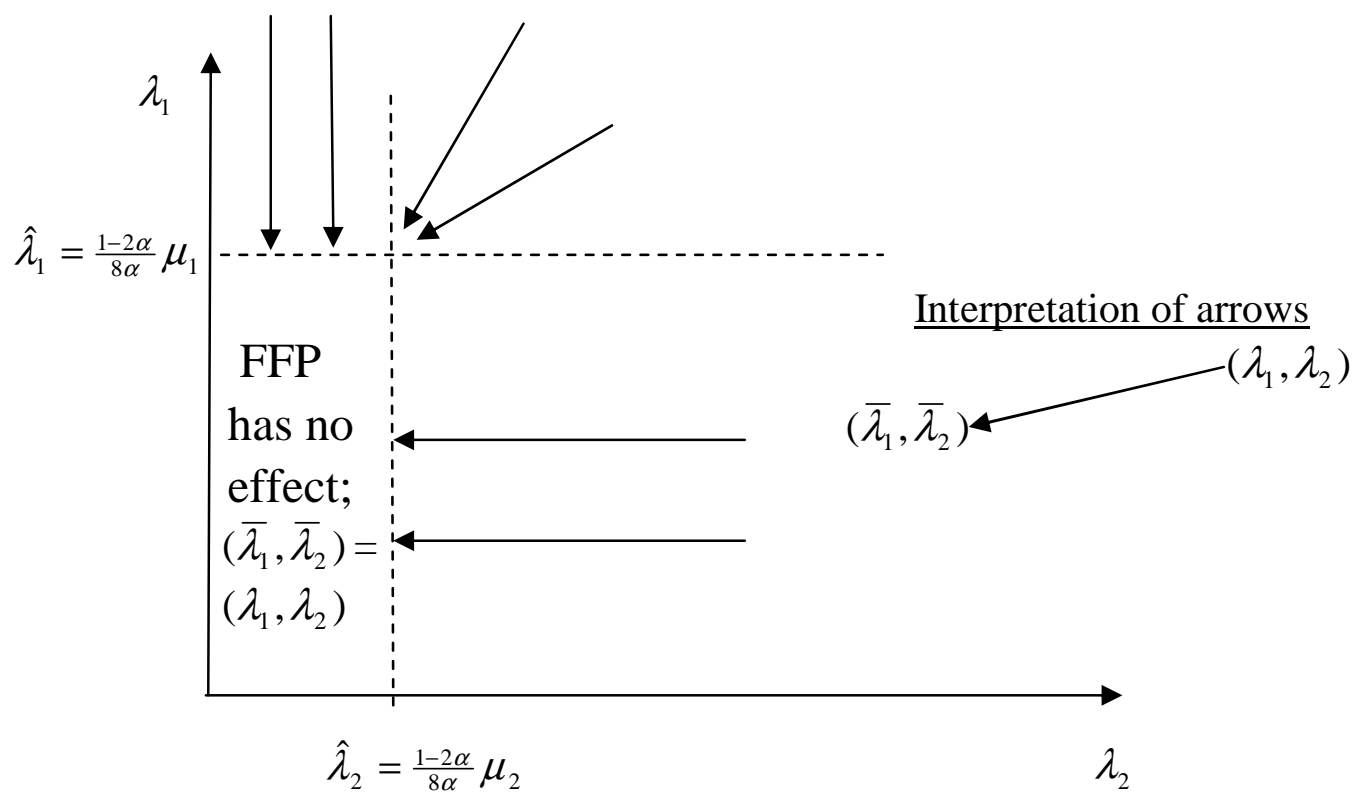

Figure 2; laissez-faire/FFP equilibrium relation 
In all cases the FFP equilibrium values of $t_{1}, t_{2}, \bar{t}, w$ and $p_{1}, p_{2}$ continue to be described by (3.1)-(3.3) with $\lambda_{i}$ reduced to $\hat{\lambda}_{i}$ if type $i$ owners are benefactors. The following are then immediate consequences of FFP, reversing the effects of the generosity parameter increases in Proposition 4(ii), (iii), (iv) and (i) respectively:

Theorem 1 For a league where the owners of at least one type of club are benefactors, and where the supply of talent is relatively elastic $(\varepsilon>1 /(2 \beta))$, the impact of FFP will be:

(i) a reduction in the quality of all teams;

(ii) a reduction in all season ticket prices;

(iii) a reduction in the utility of all fans;

(iv) a reduction in the wage per unit of talent (if $\varepsilon<\infty$ ).

The most common regulator test for a new regulation is whether the effect on consumer surplus is positive. Clearly this test is failed by FFP - all fans are worse off, despite the fall in ticket prices that FFP induces. The reason is that the net utility of a fan of club in is $v\left(t_{i n}, \bar{t}\right)-p_{\text {in }}-x$. The effect of FFP on team qualities causes $v\left(t_{i n}, \bar{t}\right)$ to fall, but this is only partially $(50 \%)$ offset by the ticket price reduction (since $p_{\text {in }}=\frac{1}{2} v\left(t_{i n}, \bar{t}\right)$ ), and fans' utilities always fall. This negative conclusion for FFP in Theorem 1 is reinforced by its adverse impact also on player salaries in (iv).

The impact of FFP on owner utility (missing from Theorem 1) is less immediate, since the comparative static exercise in Section 3 involved changing the generosity parameters $\lambda_{i}, \lambda_{j}$, and FFP does not do this - it merely changes $t_{1}, t_{2}, \bar{t}, w$ and $p_{1}, p_{2}$ as if $\lambda_{i}$ changes to $\hat{\lambda}_{i}$ if type $i$ owners are benefactors. In fact the impact of FFP on owner utility is quite complicated. There is a "local" result, in the expected direction:

Theorem 2 For a league where the owners of at least one type of club are benefactors, but not too generous benefactors ( $\lambda_{i}$ is above but close to $\hat{\lambda}_{i}$ ), and where $\varepsilon>\alpha / \beta$, the impact of FFP will be a reduction in all owner utility levels.

Proof See appendix.

Clearly FFP is a bad thing from the welfare viewpoint, at least for a league where the supply of playing talent is relatively elastic. Not only are all consumers (fans) made worse off by the imposition of FFP regulations, but the other interested parties of players and owners are also adversely affected.

\section{FURTHER DISCUSSION}

This section offers some further remarks about various aspects of the model and the findings.

\subsection{The "large league" assumption}

The assumption of a large league consisting of large numbers of 2 types of clubs has been adopted to facilitate tractability of the model when talent supply is less than 
perfectly elastic. However the main points remain for the perfectly elastic talent supply special case if instead one assumes just 2 clubs (a small league). Indeed the first draft of this paper (available on request from the author) explored exactly this type of model; 2 clubs, $\varepsilon=\infty$ but everything else as here. The equilibrium concept is then that of Dietl et al. (2009), Lang et al. (2011), Madden (2012), Madden and Robinson (2012)), a special case of the strategic market game concept suggested for small leagues in Madden (2011), and the results are qualitatively identical to those found here for the case $\varepsilon=\infty$. The desire to bring player salary changes onto the agenda requires generalization of the talent supply assumption, and then the 2 club small league model becomes somewhat intractable because of the talent market power the 2 clubs now have, and the strategic interactions between individual clubs which appear; hence the switch to the current large league setting ${ }^{11}$, where these interactions become negligible and clear results can be derived for the whole range $\varepsilon \in[0, \infty]$.

Whether actual numbers (e.g. 18 in the EPL) are large enough to make the large league model a good approximation is a somewhat moot point. Generally concerns from regulators over market power abuse would not be triggered by such a number single figure numbers are typically needed for this. The view expressed in Madden $(2010,2011)$ is that there is room for both large and small league models in the literature, and the usefulness of the insights generated should be a main criterion for model evaluation. Here the switch to the large league has allowed the additional insights into player salary changes.

\subsection{Broadcasting}

A further simplifying feature of the model is that the only club revenues are gate revenues from ticket sales to fans, plus any benefactor fund injections. In particular there is no broadcasting income, which is nowadays a major revenue source for many clubs, particularly for the EPL from Sky for rights to cover the EPL matches. However it does seem likely that enlarging the model canvas to accommodate broadcasters and their pay-TV audiences will only accentuate the negative welfare conclusions about the impact of FFP that we have reached without them.

Two points come to mind. First, the primary impact of FFP that has been brought to light here is the likely negative effect on team qualities and on the overall league quality. Almost surely this will have a negative welfare affect on the second category of consumers who now enter the picture, namely the pay-TV audiences, who have strong preference for the quality aspect (see Forrest et al. (2005)). But, secondly, this in turn is likely to have a negative knock-on affect on the willingness of broadcasters to bid for the league's TV coverage rights, which in turn will further reduce club revenues, and the overall league quality will again spiral down. Both these negative affects are detailed in Madden and Pezzino (2011), whose focus is broadcaster regulation, rather than the FFP regulation of clubs. If the UK authorities did impose FFP on the EPL, the uniform negative welfare consequences for fans, players and

\footnotetext{
${ }^{11}$ Madden (2011) also refers to the large league concept as an alternative to the game-theoretic concepts. Madden (2010) previously explored a large league model, but with profit-maximizing clubs and perfectly inelastic talent supply, more appropriate for the major North American sports leagues than European soccer.
} 
owners reported earlier may well be magnified by the broadcasting dimension, and spread to pay-TV audiences as well as the audiences of stadium fans.

\subsection{Relatively inelastic talent supply}

The paper has suggested that the assumption of a relatively elastic supply of talent to a European soccer league such as the EPL is a natural one, post-Bosman. In defence, some casual remarks are that the EPL has enjoyed an influx of non-gate revenue in the last two decades, not only from benefactors but also from pay-TV broadcasters. During the 1990s the influx led to the arrival in the EPL of many high quality players from elsewhere in Europe, and from the rest of the world (large increase in " $t_{1}+t_{2} "$ ) with some wage inflation (increase in " $w "$ ), and perhaps a relatively high elasticity. But it also seems that the rate of change of aggregate quality with respect to wage changes may have abated somewhat recently, i.e. talent supply to the EPL may have become more inelastic. This is no more than a casual conjecture stemming from two observations. First, by now, the EPL is already home to many of the world's best players, and attempts by benefactors to increase their team quality may be leading more to redistribution of talent within the EPL, rather than player import from abroad. Secondly, there does seem to be a particularly high level of recent and ongoing wage inflation in the EPL. Together these observations point towards relatively small changes in " $t_{1}+t_{2}$ " recently being associated with relatively large changes in " $w "$, perhaps indicating a relatively inelastic talent supply of late.

These observations flag up the question of the theoretical consequences of relatively inelastic talent supply: does negation of the previous relatively elastic talent supply assumption rescue FFP from the uniformly negative welfare consequences in Theorems 1 and 2? The answer is yes, to an extent, since there will be some winners now, as opposed to the uniform losers before. But, critically, the consequences for consumers (the usual regulator focus) may still be uniformly negative.

Note first that, from Proposition 4(i) and Lemma 3 and for any $\varepsilon>0$, FFP will always reduce $\bar{t}$ and so (if $\varepsilon<\infty$ ) players will be worse off. Also, since the reduction in $\bar{t}$ implies that at least one of $t_{1}$ or $t_{2}$ must fall, at least one set of fans is always made worse off by FFP. A nice special case (details omitted) shows how both sets of fans may still be made worse even at low $\mathcal{E}$, and the only winners are owners. Suppose that $\varepsilon>0$ but small, and that both owner types are benefactors with generosity parameters that are proportional to fanbase $\left(\lambda_{i}=k \mu_{i}\right.$ for some $\left.k>\frac{1-2 \alpha}{8 \alpha}\right)$. Then FFP has no effect on the laissez-faire relative team qualities (and hence on competitive balance), but causes absolute team qualities to decline proportionately (a little), bringing about a reduction in season ticket prices and a (relatively large) fall in the wage. But, exactly as before, the fall in ticket prices fails to compensate fans for the drop in quality, and all fans suffer a utility loss, accompanied by a continuing negative effect on player salaries. The only winners here are the owners. Because of the relative inelasticity of talent supply and the strategic complementarity, owners under laissez-faire end up paying large sums to increase team quality only a little they are engaged in what a number of authors have referred to as a "rat-race". FFP frees them from this expenditure spiral, producing only a relatively small drop in quality (with no change in competitive balance), which leaves owners better off, but not of course the players or fans. It is then perhaps not surprising that support for FFP 
has been expressed by benefactor owners in the EPL of both big clubs (Roman Abramovich at Chelsea) and small clubs (Dave Whelan at Wigan Athletic), and that the vast majority of the larger European clubs (in ECA) voted for UEFA's adoption of FFP.

\subsection{Empirical issues}

The theoretical model has made a number of simplifying assumptions in order to provide an integrated, coherent argument regarding FFP. However 2 particular assumptions are central to the paper, and lend themselves to empirical investigation. The first has already been indicated in the previous sub-section and spawns the question: what is a reasonable value of the elasticity of talent supply to the EPL, and how has it changed over the last 20 years? Although some anecdotal pointers were provided, there does seem to be a lack of any serious scientific estimates. It is clear from our findings that this elasticity is important, the strongly negative conclusions regarding FFP following if it is high, with more nuanced conclusions otherwise. The second central assumption is that fan utility, and the implied ticket demand and gate revenues, are increasing in both home and away team qualities. This too is important here in that the effects of absolute team qualities on fan utilities dominate the fan welfare evaluations, changes in relative qualities and competitive balance being irrelevant. There is scientific evidence in favour of this second assumption, in the cited Buraimo and Simmons (2008), but further confirmation of their findings would be valuable.

\section{CONCLUSIONS}

The paper has provided a novel model of owner objectives in a sports league, encompassing the standard profit and win maximizers, and bringing in benefactors who inject their own funds to enhance team quality. The motivation assumed to be behind the benefactor behaviour is a pure consumption motive, its value depending on the quality of the team and the league, analogous maybe to race-horse ownership. Benefactors seem to be present in European soccer, especially the EPL, but UEFA's recently published FFP regulations aim to preclude positive benefactor fund injections for the direct enhancement of team quality (by payment of salaries or transfer fees). Although the FFP regulations do not preclude a benefactor meeting costs associated with longer-run investments, such as youth development, tangible fixed assets, and so on, they will preclude the direct team quality enhancements that are our focus. For UEFA the regulations will shortly become a pre-condition of entry to its European level club competitions, and it has been suggested that FFP might be adopted by the EPL, forcing all its clubs to comply. Assuming talent supply is relatively elastic (given the fierce inter-league competition for players in European soccer), the model shows that such a regulation will lead to a reduction in all team qualities, and this will lead to a Pareto disimprovement for all fans of the league, as well as a fall in owner utilities and player wages.

Although a relatively inelastic talent supply to the league softens the extreme negativity of these conclusions, it may easily remain the case that all fans and players are made worse off by FFP, with only owners gaining. Whilst this suggests how a regulation like FFP might come to be adopted in a world where clubs have political power, there is still nothing here to recommend that FFP should be adopted, in 
particular against the usual consumer surplus criterion, either in the context of an individual league or in UEFA's pan-European context.

If there is a sound case in economic theory for FFP as a regulatory device, it seems to me that such a case remains to be made. 


\section{REFERENCES}

Buraimo, B., and Simmons, R., (2008), "Do sports fans really value uncertainty of outcome? Evidence from the English Premier League", International Journal of Sports Finance, vol. 3, p. 146-155.

Buraimo, B., and Simmons, R., (2009), "A tale of two audiences: spectators, television viewers and outcome uncertainty in Spanish football", Journal of Economics and Business, vol. 61, p. 326-338.

Buraimo, B., Forrest D., and and Simmons, R., (2009), "Insights for clubs from modelling match attendance in football", Journal of the Operational Research Society, vol. 60, p. 147-155.

DeGennaro, R.P.,(2003), "The utility of sport and returns to ownership", Journal of Sports Economics, vol. 4(2), p.145-153.

Dietl, H.M., Lang, M. and Werner, S., (2009), "Social welfare in a sports league with profit-maximizing and win-maximizing clubs", Southern Economic Journal, vol. 76(2), p. 375-396.

Forrest D. and Simmons R., (2002), "Outcome uncertainty and attendance demand in sport; the case of English soccer", Journal of the Royal Statistical Society (Series D, The Statistician), vol. 51(2), p. 229-241.

Forrest D., Simmons R. and Buraimo B., (2005), "Outcome uncertainty and the couch potato audience”, Scottish Journal of Political Economy, vol. 52(4), p.641-661.

Fort, R. and Quirk, J., (2011), "Optimal competitive balance in a season ticket league", available at http://www.rodneyfort.com/Academic/Academic.html, (forthcoming in Economic Inquiry).

Franck, E., (2010), "Private firm, public corporation or member's association governance structures in European football", International Journal of Sports Finance, vol. 5, p. 108-127.

Gamrat, F.A. and Sauer R.D., (2000), " The utility of sport and returns to ownership; evidence from the thoroughbred market", Journal of Sports Economics, vol. 1(3), p. 219-235.

Garcia-del-Barrio, P., and Szymanski, S., (2009), "Goal! Profit maximization versus win maximization in soccer”, Review of Industrial Organization, vol. 34, p. 45-68.

Kesenne, S., (2007a), The Economic Theory of Professional Team Sports; an Analytical Treatment: Edward Elgar.

Kesenne, S., (2007b), "The peculiar international economics of professional football in Europe", Scottish Journal of Political Economy, vol. 54(3), p. 388-399. 
Lang, M., Grossman, M. and Theiler, P., (2011), "The sugar daddy's game; how wealthy investors change competition in professional team sports", Journal of Institutional and Theoretical Economics, vol. 167(4), p. 557-577.

Madden, P., (2010), "The regulation of a large sports league", University of Manchester Economics Discussion Paper EDP-1007.

Madden, P., (2011), "Game theoretic analysis of basic sports leagues", Journal of Sports Economics, vol. 12(4), p. 407-431.

Madden, P., (2012), "Fan welfare maximization as a club objective in a professional sports league", European Economic Review, vol. 56, p. 560-578.

Madden, P. and Pezzino, M., (2011), "Sports league quality, broadcaster TV rights income and price regulation of sports channels", paper presented to the EARIE conference, Stockholm, September 2011.

Madden, P. and Robinson, T., (2012), "Supporter influence on club governance in a sports league; a 'utility maximization' model”, Scottish Journal of Political Economy, forthcoming.

Rosen, S., (1981), "The economics of superstars", American Economic Review, vol. 71, p. 845-858.

UEFA (2010a), “The European club footballing landscape; club licensing benchmark report financial year 2009”, Nyon, UEFA.

UEFA (2010b), "UEFA club licensing and financial fair play regulations", Nyon, UEFA. 


\section{APPENDIX}

\section{Proof of Lemma 1}

Proof of "only if" If $\bar{t}>0$ and $t_{i n}>0$ solves (2.2) then the necessary first-order condition is;

$$
\lambda_{i} u^{\prime}\left[t_{i n}^{\alpha} \bar{t}^{\beta}\right] \alpha t_{i n}^{\alpha-1} \bar{t}^{\beta}+\frac{1}{2} \alpha \mu_{i} t_{i n}^{2 \alpha-1} \bar{t}^{2 \beta}=w
$$

Writing $v \equiv t_{i n}^{\alpha} \bar{t}^{\beta}>0$, the first-order condition becomes;

$$
\lambda_{i} u^{\prime}[v] \alpha v+\frac{1}{2} \alpha \mu_{i} v^{2}=w t_{\text {in }}
$$

The solution involves zero profits if and only if;

$$
\frac{1}{4} \mu_{i} t_{i n}^{2 \alpha} \bar{t}^{2 \beta}=\frac{1}{4} \mu_{i} v^{2}=w t_{\text {in }}
$$

Hence, if $t_{\text {in }}$ solves (2.2) with zero profits;

$$
\lambda_{i} u^{\prime}[v] \alpha v+\frac{1}{2} \alpha \mu_{i} v^{2}=\frac{1}{4} \mu_{i} v^{2} \Rightarrow \lambda_{i} u^{\prime}[v]=\frac{1-2 \alpha}{4 \alpha} \mu_{i} v
$$

The solution to the differential equation in (A3) is;

$$
\lambda_{i} u[v]=\frac{1-2 \alpha}{8 \alpha} \mu_{i} v^{2}+A
$$

This completes "only if".

Proof of "if" Suppose $\lambda_{i} u[v]=\frac{1-2 \alpha}{8 \alpha} \mu_{i} v^{2}+A$ where $v=t_{\text {in }}^{\alpha} \bar{t}^{\beta}>0$. The objective function in (2.2) becomes $\frac{1}{8 \alpha} \mu_{i} t_{i n}^{2 \alpha} \bar{t}^{2 \beta}+A-w t_{i n}$, which is concave in $t_{i n}$. The solution is therefore characterized by the first-order condition $\frac{1}{4} \mu_{i} t_{i n}^{2 \alpha-1} \bar{t}^{2 \beta}-w=0$ which implies the zero profits of (A2).

Remaining proofs use the shorthand notation: $a_{i}=\left(\frac{1}{4} \mu_{i}+\lambda_{i}\right)$

Proof of Lemma 2 (3.1) implies;

$$
t_{j}=t_{i}\left(a_{j} / a_{i}\right)^{\frac{1}{1-2 \alpha}} \Rightarrow t_{i}+t_{j}=t_{i} a_{i}^{-\frac{1}{1-2 \alpha}}\left(a_{i}^{\frac{1}{1-2 \alpha}}+a_{j}^{\frac{1}{1-2 \alpha}}\right)
$$

If $\varepsilon=0$, (3.2) implies $t_{i}+t_{j}=1$, which, when combined with (A4), (3.1) and (3.3) gives unique equilibrium values for $t_{i}, t_{j}$ (hence $\bar{t}$ ), $w$ and $p_{i}, p_{j}$.

If $\varepsilon \in(0, \infty),(3.1)$ and (3.2) imply;

$$
2^{1-\frac{1}{\varepsilon}} \alpha a_{i} t_{i}^{2 \alpha-1} \bar{t}^{-2 \beta-\frac{1}{\varepsilon}}=1
$$

(A4) and (3.2) imply;

$$
\bar{t}=\frac{1}{2} t_{i} a_{i}^{-\frac{1}{1-2 \alpha}}\left(a_{i}^{\frac{1}{1-2 \alpha}}+a_{j}^{\frac{1}{1-2 \alpha}}\right)
$$

Substituting (A6) into (A5) gives;

$$
2^{1-2 \beta} \alpha t_{i}^{2 \alpha+2 \beta-1-\frac{1}{\varepsilon}} a_{i}^{\frac{1-2 \alpha-2 \beta+\frac{1}{\varepsilon}}{1-2 \alpha}}\left(a_{i}^{\frac{1}{1-2 \alpha}}+a_{j}^{\frac{1}{1-2 \alpha}}\right)^{2 \beta-\frac{1}{\varepsilon}}=1,
$$

which gives a unique equilibrium value for $t_{i}$ (hence $t_{j}, \bar{t}$ ), and (3.2) and (3.3) complete with the unique values for $w$ and $p_{i}, p_{j}$.

For $\varepsilon=\infty$ the result follows from the argument for $\varepsilon \in(0, \infty)$ putting $1 / \varepsilon=0$.

Proof of Proposition 1 Suppose $\varepsilon<\infty$. Equilibrium conditions (3.1)and (3.2) imply;

$$
\begin{aligned}
& 2 \alpha a_{i} w^{2 \beta \varepsilon-1}=2^{2 \beta} t_{i}^{1-2 \alpha} \\
& 2 \alpha a_{j} w^{2 \beta \varepsilon-1}=2^{2 \beta} t_{j}^{1-2 \alpha}\left[=2^{2 \beta}\left(w^{\varepsilon}-t_{i}\right)^{1-2 \alpha}\right]
\end{aligned}
$$


Hence, with $y \equiv[1+\varepsilon(1-2 \alpha-2 \beta)] /(1-2 \alpha)>0$;

$$
\begin{aligned}
t_{i} & =w^{\varepsilon}-\left[2^{1-2 \beta} \alpha a_{j} w^{2 \beta \varepsilon-1}\right]^{\frac{1}{1-2 \alpha}} \\
t_{i} & =\left[2^{1-2 \beta} \alpha a_{i} w^{2 \beta \varepsilon-1}\right]^{\frac{1}{1-2 \alpha}} \\
w^{y} & =\left[2^{1-2 \beta} \alpha a_{j}\right]^{\frac{1}{1-2 \alpha}}+\left[2^{1-2 \beta} \alpha a_{i}\right]^{\frac{1}{1-2 \alpha}}
\end{aligned}
$$

Since $y>0$, it follows from (A11) that $w$, and hence (if $\varepsilon>0$ ) $\bar{t}$, are increasing in $a_{i}$, hence in $\lambda_{i}$, establishing (ii) when $\varepsilon<\infty$, and (iii). It then follows from (A10) that $t_{j}$ is increasing in $a_{i}$, hence in $\lambda_{i}$, iff $2 \beta \varepsilon-1>0$, or $\varepsilon>1 /(2 \beta)$, and decreasing if $\varepsilon<1 /(2 \beta)$, completing (iv) when $\varepsilon<\infty$.

From (A10) and (A11);

$$
\begin{aligned}
t_{i}^{1-2 \alpha} & =2^{1-2 \beta} \alpha a_{i} w^{2 \beta \varepsilon-1} \\
& =\left(2^{1-2 \beta} \alpha\right)^{1+\frac{2 \beta \varepsilon-1}{y(1-2 \alpha)}} a_{i}\left(a_{i}^{\frac{1}{1-2 \alpha}}+a_{j}^{\frac{1}{1-2 \alpha}}\right)^{\frac{2 \beta \varepsilon-1}{y}}
\end{aligned}
$$

Now $t_{i}$ increases with $\lambda_{i}$ iff (A12) increases with $a_{i}$. The corresponding derivative is positive iff;

$$
\left(a_{i}^{\frac{1}{1-2 \alpha}}+a_{j}^{\frac{1}{1-2 \alpha}}\right)+\frac{2 \beta \varepsilon-1}{y(1-2 \alpha)} a_{i}^{\frac{1}{1-2 \alpha}}=\left[1+\frac{2 \beta \varepsilon-1}{y(1-2 \alpha)}\right] a_{i}^{\frac{1}{1-2 \alpha}}+a_{j}^{\frac{1}{1-2 \alpha}}>0
$$

which is always true since $1+\frac{2 \beta \varepsilon-1}{y(1-2 \alpha)}=\frac{\varepsilon}{y} \geq 0$. This proves (i) when $\varepsilon<\infty$.

If $\varepsilon=\infty$, so $w=1$ (and hence (iii)), (3.1)-(3.3) imply;

$$
2 \alpha a_{i} t_{i}^{2 \alpha-1} \bar{t}^{2 \beta}=1
$$

Therefore;

$$
t_{i}^{1-2 \alpha-2 \beta}=2 \alpha a_{i}^{1-2 \beta}\left[a_{i}+a_{j}\right]^{2 \beta}
$$

from which (i) and (iv) follow ( $\varepsilon<1 /(2 \beta)$ is now vacuous), and hence (ii).

Proof of Proposition 2 An increase in $\lambda_{i}$ produces a Pareto improvement for type $i$ club fans iff it increases $v\left(t_{i}, \bar{t}\right)=t_{i}^{\alpha} \bar{t}^{\beta}$. This is always true since an increase in $\lambda_{i}$ increases both $t_{i}$ and (at least weakly) $\bar{t}$, from Proposition 1. For the increase to produce a Pareto improvement for type $j$ club fans requires that $v\left(t_{j}, \bar{t}\right)=t_{j}^{\alpha} \bar{t}^{\beta}$ increases; if $\varepsilon=\infty$ this is again immediate from Proposition 1. Suppose $\varepsilon<\infty$. Then $v\left(t_{j}, \bar{t}\right)=t_{j}^{\alpha} \bar{t}^{\beta}=t_{j}^{\alpha} w^{\beta \varepsilon} 2^{-\beta}$. Using (A10), with $j$ rather than $i$, gives;

$$
v\left(t_{j}, \bar{t}\right)=\left[2^{1-2 \beta} \alpha a_{j}\right]^{\frac{\alpha}{1-2 \alpha}} w^{z} 2^{-\beta} \text { where } z \equiv \frac{\alpha(2 \beta \varepsilon-1)+\beta \varepsilon(1-2 \alpha)}{1-2 \alpha}=\frac{\beta \varepsilon-\alpha}{1-2 \alpha}
$$

Since $w$ is increasing in $\lambda_{i}$, from Proposition 1, the Pareto improvement occurs if $z>0$, or $\varepsilon>\alpha / \beta$, the reverse if $\varepsilon<\alpha / \beta$.

Proof of Proposition 3 If $\varepsilon=\infty$ the result is immediate from Proposition $1\left(t_{i}, t_{j}\right.$ increase with $\lambda_{i}$, and $w$ is constant) and (3.5). For $\varepsilon<\infty$ the result for $U_{i}$ is similarly immediate from Proposition 1 and (3.5). For $U_{j}$, (A10) with $j$ rather than $i$, gives;

$$
w t_{j}=\left[2^{1-2 \beta} \alpha a_{j}\right]^{\frac{1}{1-2 \alpha}} w^{\frac{2 \beta \varepsilon-1}{1-2 \alpha}+1}
$$


The exponent on $w$ on the right hand side is $\frac{2 \beta \varepsilon-1}{1-2 \alpha}+1=\frac{2 \beta \varepsilon-2 \alpha}{1-2 \alpha}>0$ if $\varepsilon>\alpha / \beta$, ensuring that $w t_{j}$ and hence $U_{j}$ is increasing in $w$, which is increasing in $\lambda_{i}$ from Proposition 1. Conversely the $w$ exponent is negative if $\varepsilon<\alpha / \beta$, and $U_{j}$ is decreasing in $\lambda_{i}$.

\section{Proof of Lemma 3}

(4.1) is a well-behaved concave programming problem whose Lagrangean is, with $\eta_{\text {in }}$ denoting the Lagrange multiplier;

$$
L\left(t_{\text {in }}, \eta_{\text {in }}\right)=a_{i} t_{\text {in }}^{2 \alpha} \bar{t}^{2 \beta}-w t_{\text {in }}+\eta_{\text {in }}\left\{\frac{1}{4} \mu_{i} t_{\text {in }}^{2 \alpha} \bar{t}^{2 \beta}-w t_{\text {in }}\right\}
$$

The necessary and sufficient conditions for a solution are;

$$
\begin{aligned}
& \partial L / \partial t_{i n}=2 \alpha a_{i} t_{i n}^{2 \alpha-1} \bar{t}^{2 \beta}-w+\eta_{i n}\left\{2 \alpha \frac{1}{4} \mu_{i} t_{i n}^{2 \alpha-1} \bar{t}^{2 \beta}-w\right\}=0 \\
& \quad \eta_{i j} \geq 0, \frac{1}{4} \mu_{i} t_{i n}^{2 \alpha} \bar{t}^{2 \beta}-w t_{i n} \geq 0 \text { and } \eta_{i n}\left\{\frac{1}{4} \mu_{i} t_{i n}^{2 \alpha} \bar{t}^{2 \beta}-w t_{i n}\right\}=0
\end{aligned}
$$

A solution with $\eta_{i n}>0, \frac{1}{4} \mu_{i} t_{i n}^{2 \alpha} \bar{t}^{2 \beta}-w t_{i n}=0$ (and so FFP is binding) occurs if and only if;

$\eta_{\text {in }}=\left\{2 \alpha a_{i} t_{\text {in }}^{2 \alpha-1} \bar{t}^{2 \beta}-w\right\} /\left\{w-2 \alpha \frac{1}{4} \mu_{i} t_{i n}^{2 \alpha-1} \bar{t}^{2 \beta}\right\}=\left\{\frac{8 \alpha}{\mu_{i}}\left(\frac{1}{4} \mu_{i}+\lambda_{i}\right)-1\right\} /(1-2 \alpha)>0$

And this is true if and only if $\lambda_{i}>\hat{\lambda}_{i}=\mu_{i} \frac{1-2 \alpha}{8 \alpha}$, and the owner is a benefactor; in this case talent demand is given by $\frac{1}{4} \mu_{i} t_{i n}^{2 \alpha-1} \bar{t}^{2 \beta}=w$, which defines the talent demand of a win-maximizer - (3.1) with $\bar{\lambda}_{i} \equiv \hat{\lambda}_{i}=\mu_{i} \frac{1-2 \alpha}{8 \alpha}$.

Otherwise (if $\lambda_{i} \leq \hat{\lambda}_{i}=\mu_{i} \frac{1-2 \alpha}{8 \alpha}$ and the owner is not a benefactor) FFP is not binding, $\eta_{i n}=0$ and the solution is given by (3.1) with $\bar{\lambda}_{i} \equiv \lambda_{i}$.

Hence, under FFP, talent demands are given by (3.1), the laissez-faire talent demands, with $\left(\bar{\lambda}_{1}, \bar{\lambda}_{2}\right)=\left(\min \left[\lambda_{1}, \hat{\lambda}_{1}\right], \min \left[\lambda_{2}, \hat{\lambda}_{2}\right]\right)$. Therefore equilibria under FFP with $\left(\lambda_{1}, \lambda_{2}\right)$ coincide with laissez-faire equilibria with $\left(\bar{\lambda}_{1}, \bar{\lambda}_{2}\right)$ as defined. Existence and uniqueness of such equilibria follows from Lemma 2.

Proof of Theorem 2 Consider the case where the owners of type $i$ clubs are benefactors $\left(\lambda_{i}>\hat{\lambda}_{i}\right)$ and type $j$ owners are non-benefactors $\left(\lambda_{j} \leq \hat{\lambda}_{j}\right)$. For the type $j$ owners the result is immediate from Proposition 3 , since the effect of FFP is as if $\lambda_{i}$ falls, so $U_{j}$ falls when $\varepsilon>\alpha / \beta$. So the focus is now on $U_{i}$.

In laissez-faire the equilibrium conditions of (3.1)-(3.3) lead to (A10) and (A11) in the proof of Proposition 1 above, from which with obvious notation we have;

$$
w_{L} t_{i L}=\left(2^{1-2 \beta} \alpha\right)^{\frac{1+\varepsilon}{1+\varepsilon(1-2 \alpha-2 \beta)}} a_{i}^{\frac{1}{1-2 \alpha}}\left(a_{i}^{\frac{1}{1-2 \alpha}}+a_{j}^{\frac{1}{1-2 \alpha}}\right)^{\frac{2 \beta \varepsilon-2 \alpha}{1+\varepsilon(1-2 \alpha-2 \beta)}}
$$

Substitution into (3.5) gives the following expression for laissez-faire equilibrium utility of type $i$ owners;

$$
U_{i L}=\frac{1-2 \alpha}{2 \alpha}\left(2^{1-2 \beta} \alpha\right)^{\frac{1+\varepsilon}{1+\varepsilon(1-2 \alpha-2 \beta)}} a_{i}^{\frac{1}{1-2 \alpha}}\left(a_{i}^{\frac{1}{1-2 \alpha}}+a_{j}^{\frac{1}{1-2 \alpha}}\right)^{\frac{2 \beta \varepsilon-2 \alpha}{1+\varepsilon(1-2 \alpha-2 \beta)}}
$$

In FFP the equilibrium conditions are again (3.1)-(3.3), but with the substitution of $\frac{1}{4} \mu_{i}$ for $2 \alpha\left(\frac{1}{4} \mu_{i}+\lambda_{i}\right)$. The same amendment to (A10) and (A11) leads to the FFP version of (A13):

$$
w_{F} t_{i F}=\left(2^{1-2 \beta} \alpha\right)^{\frac{1+\varepsilon}{1+\varepsilon(1-2 \alpha-2 \beta)}}\left(\frac{\mu_{i}}{8 \alpha}\right)^{\frac{1}{1-2 \alpha}}\left[\left(\frac{\mu_{i}}{8 \alpha}\right)^{\frac{1}{1-2 \alpha}}+a_{j}^{\frac{1}{1-2 \alpha}}\right]^{\frac{2 \beta \varepsilon-2 \alpha}{1+\varepsilon(1-2 \alpha-2 \beta)}}
$$


Substitution of the equilibrium conditions into (2.3) now produces the alternative to (3.5), $U_{i}=4 \frac{\lambda_{i}}{\mu_{i}} w t_{i}$, and (A15) then gives the FFP version of (A14);

$$
U_{i F}=4 \frac{\lambda_{i}}{\mu_{i}}\left(2^{1-2 \beta} \alpha\right)^{\frac{1+\varepsilon}{1+\varepsilon(1-2 \alpha-2 \beta)}}\left(\frac{\mu_{i}}{8 \alpha}\right)_{i}^{\frac{1}{1-2 \alpha}}\left[\left(\frac{\mu_{i}}{8 \alpha}\right)_{i}^{\frac{1}{1-2 \alpha}}+a_{j}^{\frac{1}{1-2 \alpha}}\right]^{\frac{2 \beta \varepsilon-2 \alpha}{1+\varepsilon(1-2 \alpha-2 \beta)}}
$$

Now $U_{i F}-U_{i L}$ has the sign of;

$$
\Delta=\frac{8 \alpha}{1-2 \alpha} \frac{\lambda_{i}}{\mu_{i}}\left(\frac{\mu_{i}}{8 \alpha}\right)^{\frac{1}{1-2 \alpha}}\left[\left(\frac{\mu_{i}}{8 \alpha}\right)^{\frac{1}{1-2 \alpha}}+a_{j}^{\frac{1}{1-2 \alpha}}\right]^{\frac{2 \beta \varepsilon-2 \alpha}{1+\varepsilon(1-2 \alpha-2 \beta)}}-a_{i}^{\frac{1}{1-2 \alpha}}\left(a_{i}^{\frac{1}{1-2 \alpha}}+a_{j}^{\frac{1}{1-2 \alpha}}\right)^{\frac{2 \beta \varepsilon-2 \alpha}{1+\varepsilon(1-2 \alpha-2 \beta)}}
$$

Taking the partial derivative and rearranging gives;

$$
\begin{aligned}
& \partial \Delta / \partial \lambda_{i}=\frac{8 \alpha}{\mu_{i}(1-2 \alpha)}\left(\frac{\mu_{i}}{8 \alpha}\right)^{\frac{1}{1-2 \alpha}}\left[\left(\frac{\mu_{i}}{8 \alpha}\right)^{\frac{1}{1-2 \alpha}}+a_{j}^{\frac{1}{1-2 \alpha}}\right]^{\frac{2 \beta \varepsilon-2 \alpha}{1+\varepsilon(1-2 \alpha-2 \beta)}} \\
& +a_{i}^{\frac{1}{1-2 \alpha}-1}\left(a_{i}^{\frac{1}{1-2 \alpha}}+a_{j}^{\frac{1}{1-2 \alpha}}\right)^{\frac{2 \beta \varepsilon-2 \alpha}{1+\varepsilon(1-2 \alpha-2 \beta)}-1}\left\{\left(\frac{2 \alpha-2 \beta \varepsilon}{1+\varepsilon(1-2 \alpha-2 \beta)}-\frac{1}{1-2 \alpha}\right) a_{i}^{\frac{1}{1-2 \alpha}}-\frac{1}{1-2 \alpha} a_{j}^{\frac{1}{1-2 \alpha}}\right\}
\end{aligned}
$$

Evaluating this at the border where $\lambda_{i}=\hat{\lambda}_{i}=\mu_{i} \frac{1-2 \alpha}{8 \alpha}$, or $a_{i}=\frac{\mu_{i}}{8 \alpha}$, (implying $\Delta=0$ ) gives;

$$
\begin{aligned}
& \partial \Delta / \partial \lambda_{i}=\frac{1}{1-2 \alpha} a_{i}^{\frac{1}{1-2 \alpha}-1}\left[a_{i}^{\frac{1}{1-2 \alpha}}+a_{j}^{\frac{1}{1-2 \alpha}}\right]^{\frac{2 \beta \varepsilon-2 \alpha}{1+\varepsilon(1-2 \alpha-2 \beta)}} \\
& +a_{i}^{\frac{1}{1-2 \alpha}-1}\left(a_{i}^{\frac{1}{1-2 \alpha}}+a_{j}^{\frac{1}{1-2 \alpha}}\right)^{\frac{2 \beta \varepsilon-2 \alpha}{1+\varepsilon(1-2 \alpha-2 \beta)}-1}\left\{\left(\frac{2 \alpha-2 \beta \varepsilon}{1+\varepsilon(1-2 \alpha-2 \beta)}-\frac{1}{1-2 \alpha}\right) a_{i}^{\frac{1}{1-2 \alpha}}-\frac{1}{1-2 \alpha} a_{j}^{\frac{1}{1-2 \alpha}}\right\}
\end{aligned}
$$

After cancellation of some terms this is strictly positive iff $\frac{2 \alpha-2 \beta \varepsilon}{1+\varepsilon(1-2 \alpha-2 \beta)} a_{i}^{\frac{1}{1-2 \alpha}}>0$, which is true iff $\varepsilon<\alpha / \beta$. It follows that $\Delta>0$, or $U_{i F}>U_{i L}$ if $\lambda_{i}$ is above $\hat{\lambda}_{i}$ but sufficiently close to it, and $\varepsilon<\alpha / \beta$. Conversely if $\varepsilon>\alpha / \beta$ then $U_{i F}<U_{i L}$ if $\lambda_{i}$ is above $\hat{\lambda}_{i}$ but sufficiently close to it.

The case where both types of owners are benefactors applies the above argument for type $i$ owners to both types. The formula for $\Delta$, now $\Delta_{i}, 1=1,2$, is;

$$
\Delta_{i}=\frac{4 \lambda_{i}}{\mu_{i}}\left(\frac{\mu_{i}}{8 \alpha}\right)^{\frac{1}{1-2 \alpha}}\left[\left(\frac{\mu_{i}}{8 \alpha}\right)^{\frac{1}{1-2 \alpha}}+\left(\frac{\mu_{j}}{8 \alpha}\right)^{\frac{1}{1-2 \alpha}}\right]^{\frac{2 \beta \varepsilon-2 \alpha}{1+\varepsilon(1-2 \alpha-2 \beta)}}-\frac{1-2 \alpha}{2 \alpha} a_{i}^{\frac{1}{1-2 \alpha}}\left(a_{i}^{\frac{1}{1-2 \alpha}}+a_{j}^{\frac{1}{1-2 \alpha}}\right)^{\frac{2 \beta \varepsilon-2 \alpha}{1+\varepsilon(1-2 \alpha-2 \beta)}}
$$

Similar to above, it follows that $\partial \Delta_{i} / \partial \lambda_{i}>0$ and $\partial \Delta_{i} / \partial \lambda_{j}>0$ where $\lambda_{i}=\hat{\lambda}_{i}=\mu_{i} \frac{1-2 \alpha}{8 \alpha}$, or $a_{i}=\frac{\mu_{i}}{8 \alpha}$, iff $\varepsilon<\alpha / \beta$. Thus $U_{i F}<U_{i L}, i=1,2$ if $\varepsilon>\alpha / \beta$, and $\lambda_{i}$ is above $\hat{\lambda}_{i}$ but sufficiently close to it for $i=1,2$. 